\title{
Renin and Renin mRNA in Proximal Tubules of the Rat Kidney
}

\author{
M. Chen, M. P. Harris, D. Rose, A. Smart, X.-R. He, M. Kretzler, J. P. Briggs, and J. Schnermann
}

Departments of Physiology and Internal Medicine, The University of Michigan, Ann Arbor, Michigan 48109

\begin{abstract}
The present study was undertaken to assess the presence of renin enzymatic activity and renin mRNA in proximal tubules of rat kidneys, and to determine the effect of converting enzyme inhibition (CEI) on proximal tubule renin gene expression. Proximal convoluted tubules (PCT), proximal straight tubules (PST), outer medullary collecting ducts (OMCD), and glomeruli (Gloms) were isolated by microdissection. Renin activity was measured in sonicated segments by radioimmunoassay. Renin mRNA levels were assessed using a quantitative PCR. Renin activity in PCT averaged $51 \pm 15 \mu \mathrm{GU} / \mathrm{mm}$ compared to $405 \pm 120 \mu \mathrm{GU} /$ glomerulus. No measurable renin activity was found in PST and OMCD. Renin activity in both glomeruli and tubules had the same pH optimum, between 7.0 and 7.5. Renin mRNA was consistently detectable in cDNA prepared from PCT and PST, although its abundance per $\mathrm{mm}$ tubule was about 1/500th that found in one glomerulus. Renin mRNA was not detectable in OMCD. Tubular renin PCR product identity was confirmed by restriction digestion. CEI administration increased glomerular renin activity and renin mRNA, but not proximal tubular renin. The absence of a stimulatory effect of CEI on proximal tubule renin gene expression suggests the operation of different intracellular signals in control of renin synthesis in the proximal tubule than in the vascular compartment. (J. Clin. Invest. 1994. 94:237-243.) Key words: Polymerase chain reaction • renin synthesis • angiotensin converting enzyme • outer medullary collecting duct $\cdot$ glomerulus
\end{abstract}

\section{Introduction}

There is evidence that the proximal tubule is a target site for the action of angiotensin II. The peptide has been shown to regulate the transport of $\mathrm{NaHCO}_{3}$ by affecting the activity of both the luminal $\mathrm{Na} / \mathrm{H}$ exchanger and the basolateral $\mathrm{Na}$ / $3 \mathrm{HCO}_{3}$ cotransporter $(1,2)$. These effects are mediated by angiotensin II receptors present in both membranes of the proximal tubule cell (3).

Angiotensin II acting on the proximal tubule may be generated in the systemic circulation and delivered to its site of action

Address correspondence to Dr. J. P. Briggs, M.D., The University of Michigan, Department of Internal Medicine, Division of Nephrology, 1150 W. Medical Center Drive, 1560 MSRB II, Ann Arbor, MI 481090676.

Received for publication 20 October 1993 and in revised form 31 March 1994.

J. Clin. Invest.

(C) The American Society for Clinical Investigation, Inc. 0021-9738/94/07/0237/07 \$2.00

Volume 94, July 1994, 237-243 through either peritubular blood or filtered fluid. Alternatively, it is possible that an autonomous tissue renin-angiotensin system generates angiotensin II at the level of the proximal tubule (4), and thereby permits autocrine interactions with its target cells. A recent study showed that the concentration of angiotensin II in proximal tubular fluid is about 500-1,000-fold higher than in plasma (5). This high concentration of angiotensin II in the proximal tubule suggests angiotensin generation in the immediate vicinity of the proximal tubule. It could be either generated by glomerular epithelial cells, or by proximal tubule cells themselves.

Immunocytochemical studies have shown the presence of angiotensinogen in the proximal tubule (6), and angiotensinogen mRNA at this site has been detected by in situ hybridization methods, indicating that the renin substrate is, in fact, synthesized by proximal tubule cells $(7,8)$. There also appears to be an abundance of angiotensin converting enzyme in both the apical and basolateral membranes of the proximal tubule (912). Evidence in support of a renin synthetic capacity in proximal tubules, however, is less convincing. While positive renin immunoreactivity was seen in apical cytoplasmic vesicles of proximal tubule cells $(13-15)$, the presence of renin mRNA could not be demonstrated with in situ hybridization methods $(14,16,17,18)$. In addition, in a recent study using reverse transcription-PCR (RT-PCR), ${ }^{1}$ no renin cDNA reaction product was detected in microdissected proximal segments of untreated rat kidneys (19).

In the present experiments we applied a quantitative RTPCR method developed in our laboratory to reassess the question of presence and relative abundance of renin mRNA in renal proximal tubules, and to compare mRNA levels with renin enzyme activity in this segment of the nephron. Furthermore, we determined the effect of converting enzyme inhibition (CEI) on proximal tubule mRNA in order to evaluate whether glomerular and tubular renin mRNA are regulated by similar mechanisms. Our data show the presence of renin transcripts in both proximal convoluted and proximal straight tubules, but not outer medullary collecting ducts, while measurable epithelial renin activity was only seen in proximal convoluted tubules. Furthermore, in contrast to the enhancing effect of converting enzyme inhibition on glomerular renin gene expression, proximal tubule renin mRNA levels were not altered with this treatment.

\section{Methods}

Animals and tissue preparation. Experiments were performed on male Sprague-Dawley rats weighing 200-250 g (Charles River Labs., Wilmington, MA). Animals were anesthetized by an intraperitoneal (i.p.)

1. Abbreviations used in this paper: $\mathrm{CEI}$, converting enzyme inhibition; GITC, guanidine isothiocyanate; GLOM, glomeruli; GU, Goldblatt units; i.p., intraperitoneal; OMCD, outer medullary collecting duct; PCT, proximal convoluted tubule; PST, proximal straight tubule; RT-PCR, reverse transcription-PCR. 
injection of Inactin (120 mg/kg; Byk Gulden, Constance, FRG). The aorta of rats was cannulated below the level of the kidneys from an abdominal midline incision. After ligating the aorta at a position between the two kidneys, the left kidney was perfused with $60 \mathrm{ml}$ of cold saline, followed by $60 \mathrm{ml}$ of cold DME (Sigma Chemical Co, St. Louis, MO) containing $1 \mathrm{mg} / \mathrm{ml}$ collagenase (Boehringer-Mannheim, Indianapolis, IN). The kidney was removed and cut into 1-2-mm-thick coronal slices. The kidney slices were incubated at $37^{\circ} \mathrm{C}$ for $22 \mathrm{~min}$ in the DME/ collagenase solution with gentle shaking. The slices were then rinsed once with ice cold phosphate buffered saline, and placed into DME medium containing $1 \%$ fetal bovine serum (Hyclone, Logan, UT). Segments were dissected with dark field illumination at $4^{\circ} \mathrm{C}$. Lengths of the dissected segments were measured. In most cases, 10 glomeruli (GLOM), $10 \mathrm{~mm}$ of proximal convoluted tubule (PCT), $10 \mathrm{~mm}$ of proximal straight tubule (PST) and $10 \mathrm{~mm}$ of outer medullary collecting duct (OMCD) were dissected and pooled to constitute one sample. Dissected glomeruli can be assumed to contain most of the cells of the juxtaglomerular apparatus and in many instances fragments of glomerular arterioles as well. The time period for dissection was limited to within $1 \mathrm{~h}$ after the digestion with collagenase. Samples were placed in $100 \mu$ guanidine isothiocyanate buffer (GITC buffer: $4 \mathrm{M}$ guanidine isothiocyanate, $25 \mathrm{mM}$ sodium acetate, $\mathrm{pH} 6.0,0.8 \% \beta$-mercaptoethanol), snap frozen in liquid nitrogen, and stored at $-80^{\circ} \mathrm{C}$.

In a separate experimental series, nine rats were used to test the effect of converting enzyme inhibition on tubule renin. Animals received either vehicle or two doses of a converting enzyme inhibitor, quinapril ( $2.5 \mathrm{mg} / \mathrm{kg}$ i.p.; Warner-Lambert/Parke Davis, Ann Arbor, MI) per day for $3 \mathrm{~d}$. On the fourth day, rats were killed and tissues were prepared as above.

Determination of mRNA. To isolate RNA, tubular, and glomerular specimens were thawed in an ice slurry bath and sonicated for $10 \mathrm{~s} .20$ $\mu \mathrm{g}$ Escherichia coli ribosomal RNA (Boehringer-Mannheim Biochemicals, Indianapolis, IN) were added as carrier, and the specimen was layered onto a gradient of cesium chloride (100 $\mu \mathrm{l} 97 \%$ and $20 \mu \mathrm{l}$ $40 \%$ cesium chloride) in a $250 \mu l$ polycarbonate ultracentrifuge tube. Specimens were centrifuged in a TLA 100 fixed angle rotor in a Beckman TL 100 ultracentrifuge (Beckman Instruments Inc, Fullertolı, CA) for $2 \mathrm{~h}$ at $16^{\circ} \mathrm{C}$ and $300,000 \mathrm{~g}$. The RNA pellet was redissolved in 0.3 $M$ sodium acetate and ethanol precipitated.

Reverse transcription was primed with $0.5 \mu \mathrm{g}_{\text {oligo }} \mathrm{dT}_{12-18}$ (Pharmacia, Piscataway, NJ), $20 \mathrm{U}$ of RNAsin (Promega Biotech, Madison, WI) and $10 \mathrm{mM}$ dithiothreitol at $65^{\circ} \mathrm{C}$ for $5 \mathrm{~min}$. The samples were then incubated at $42^{\circ} \mathrm{C}$ for $1 \mathrm{~h}$ with $100 \mathrm{U}$ of murine Molony leukemia virus (MMLV) reverse transcriptase (Superscript; GIBCO BRL, Gaithersburg, MD) in $20 \mu \mathrm{l}$ of manufacturer's buffer containing $500 \mu \mathrm{M}$ each of dATP, dGTP, dTTP, and dCTP (dNTP; Pharmacia, Piscataway, $\mathrm{NJ}$ ), and $1 \%$ bovine serum albumin (Boehringer-Mannheim Biochemicals). The cDNA samples were precipitated with $1 \mu 1$ of $5 \%$ linear acrylamide, $4 \mathrm{M}$ ammonium acetate, and $100 \%$ ethanol (20). The pellets were redissolved in Tris-EDTA buffer $(10 \mathrm{mM}$ Tris- $\mathrm{HCl}, \mathrm{pH} 7.4 ; 1$ mM EDTA, $\mathrm{pH} 8$ ) at a dilution adjusted so that each $2 \mu \mathrm{l}$ of cDNA corresponded to $1 \mathrm{~mm}$ of tubule or 1 glomerulus.

PCR reactions were performed using a Tempcycler (Coy Laboratory Products Inc., Grass Lake, MI) in a total volume of $50 \mu \mathrm{l}$ in the presence of 5 pmoles of each oligonucleotide primer, $200 \mu \mathrm{M} \mathrm{dNTP}, 10 \mathrm{mM}$ dithiothreitol, $50 \mathrm{mM} \mathrm{KCl}, 1.5 \mathrm{mM} \mathrm{MgCl}, 10 \mathrm{mM}$ Tris- $\mathrm{HCl}, \mathrm{pH} \mathrm{8.3}$, $0.001 \%$ Gelatin, $1.25 \mathrm{U}$ of AmpliTaq DNA polymerase (Perkin Elmer Cetus Corporation, Norwalk, CT), and $1.5 \mu \mathrm{Ci}{ }^{32} \mathrm{P}-\mathrm{dCTP}$ (Amersham Corp., Arlington Heights, IL). Mineral oil was layered on top of each sample to prevent evaporation of the liquid. The samples were first denatured at $94^{\circ} \mathrm{C}$ for $3.5 \mathrm{~min}$. PCR was run for 30 cycles with a denaturing phase of $1.5 \mathrm{~min}$ at $94^{\circ} \mathrm{C}$, annealing phase of $1.5 \mathrm{~min}$ at $54^{\circ} \mathrm{C}$, and extension phase of $1.5 \mathrm{~min}$ at $72^{\circ} \mathrm{C}$. The last cycle was followed by an additional incubation period of $8 \mathrm{~min}$ at $72^{\circ} \mathrm{C}$. To assess the possibility of contamination, two control reactions were included in each set of PCR amplification: a blank sample of dissection medium carried throughout the RNA and cDNA preparation steps and a $\mathrm{H}_{2} \mathrm{O}$ control for the PCR step. After amplification, PCR products were sub-

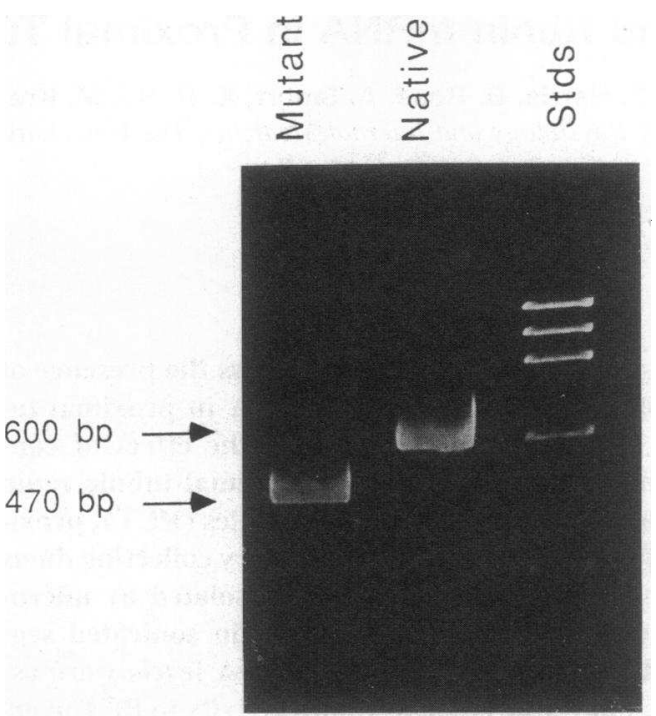

Figure 1. PCR product for native renin and mutant renin template. A segment of 130 bp between EcoRI and MscI sites in rat renin cDNA was deleted to make the mutant template ( $470 \mathrm{bp})$. PCR performed on the native template and the mutant template yielded products with expected sizes.

jected to size separation by polyacrylamide gel electrophoresis. Product bands were excised from gels and ${ }^{32} \mathrm{P}$ radioactivity was determined by liquid scintillation counting.

To quantify renin mRNA levels, a mutant renin DNA template was prepared from rat renin cDNA (pREN44.ceb; gift from Dr. K. R. Lynch; University of Virginia, Charlottesville, Virginia) by deleting a 130-bp segment between an EcoRI site at 639-bp position and an MscI site at 769-bp position (all base pair numbers refer to numbering in reference 21). To exclude other EcoRI sites present in the cDNA and vector (pGEM4; Promega Biotec, Madison, WI) a portion of the renin cDNA ( 992 bp) was first subcloned by PCR using the following primers: sense 5'-ACATCTAGACGTGGTCCTCACCAACTAC-3' (bp 435-453), and antisense 5'-ATAAAGCTTCTTAGCGGGCCAAGGCGAA-3' (bp 1,409-1,426). The product was gel purified and ligated into Bluescript-M13. The recombinant DNA was digested with EcoRI and MscI and a blunt-end ligation performed. The DNA was purified by cesium chloride banding and quantified spectrophotometrically. The following oligonucleotide primers, flanking the deletion site in the mutant renin template and positioned in separate exons (21), were used in the experimental PCR: sense 5'-TGGGTGCCCTCCACCAAGT-3' (bp 540-

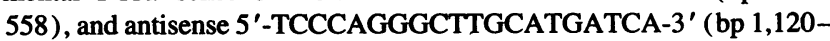
1,139). As shown in Fig. 1, PCR performed with native and mutant templates yielded products with the predicted 130-bp difference in size. The PCR amplification efficiency was tested by amplifying a four step dilution series of the mutant template in duplicates. The yield of PCR product was proportional to the starting copy number of the template, and a plot of log cDNA versus log product had an average slope equal to $0.85 \pm 0.06(n=9)$. When a dilution series of the mutant template was amplified, product was consistently detected down to about 500 copies/reaction.

PCR products obtained from cDNA prepared from rat glomeruli or tubules were quantified by comparing PCR products of sample cDNA with dilution series of the cloned mutant template ranging from 1.02 $\times 10^{3}$ to $6.40 \times 10^{5}$ copies per reaction, amplified in parallel in the same PCR run (method 1). Alternatively, four equal aliquots of sample cDNA were co-amplified with the dilution series of the mutant template (method 2). Counts per minute were corrected for product size. Linear regression lines were calculated, and the number of molecules of cDNA 


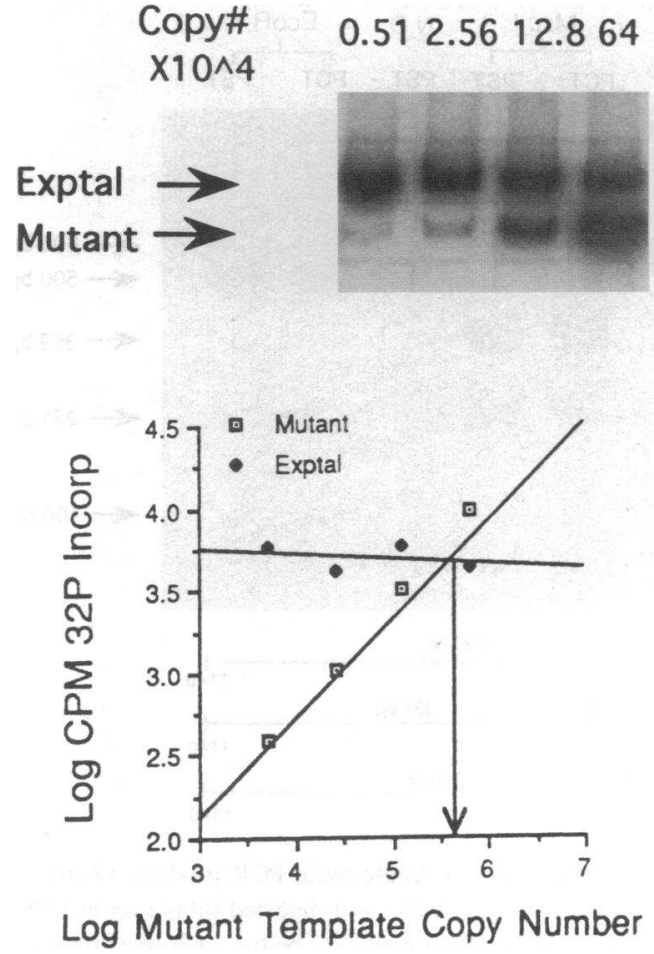

Figure 2. A representative quantitative PCR for glomerular renin. (Top) Autoradiograph of the renin competitive PCR. Each PCR reaction contained a constant aliquot of initial cDNA prepared from dissected glomeruli (Exptal), and a variable amount of a mutant template of fivefold dilution. (Bottom) Quantification of the competitive PCR. Log molecular copy number of the initial mutant templates was plotted against log radioactive counts of $P C R$ product.

in each unknown sample was determined from the intersection, as shown in Fig. 2.

To control variations in RNA isolation and efficiency of reverse transcription, PCR amplification for $\beta$-actin was also performed. The primers for $\beta$-actin were chosen empirically from human published sequences (22). The sequences of $\beta$-actin primers were as follows: sense 5'-AACCGCGAGAAGATGACCCAGATCATGTTT-3' (bp 384-413), antisense 5'-AGCAGCCGTGGCCATCTCTTGCTCGAAGTC-3' (bp 705-734).

The identity of the renin PCR product from glomeruli and tubules was determined with restriction enzyme digestion. The PCR product was digested with EcoRI and $\mathrm{MscI}$ at $37^{\circ} \mathrm{C}$ for $1 \mathrm{~h}$ in the buffer provided by the manufacturer.

To evaluate the effect of collagenase treatment and dissection time on renin mRNA we determined renin and $\beta$ actin mRNA in specimens of kidney cortex frozen immediately after harvesting and in cortical tissue subjected to the standard treatment ( $n=$ three pairs). PCR product for renin was found to be $10 \%$ lower with cDNA derived from the immediately frozen kidney, a difference that was not significant. $\beta$ actin product levels did not differ.

Determination of renin activity in glomeruli and tubules. Segments of proximal convoluted tubules, proximal straight tubules, outer medullary collecting ducts, and glomeruli were dissected as described above except that $1 \%$ bovine serum albumin instead of fetal bovine serum was added to the DME. The samples were collected in $5 \mu$ l of dissection medium with an Eppendorf pipette tip and transferred into another dish containing about $20 \mathrm{ml}$ of fresh dissection medium to wash, and the dissected samples were then transferred into $100 \mu \mathrm{l}$ of $0.1 \mathrm{M}$ sodium phosphate buffer. To determine the $\mathrm{pH}$ optimum of renin in glomerular and tubule samples, the renin assays were run in sodium phosphate
Table I. Renin Activity and Renin cDNA in Glomeruli and Tubules

\begin{tabular}{lcc}
\hline \multicolumn{1}{c}{ Sample } & Renin activity & Renin cDNA \\
\hline & $\mu G U / m m$ tubule or/glom & copy \#/mm tubule or/glom \\
Glomerulus & $405 \pm 120(n=15)$ & $313,000 \pm 179,000(n=11)$ \\
PCT & $51 \pm 15(n=16)$ & $580 \pm 210(n=15)$ \\
PST & $2.4 \pm 11.7(n=18)$ & $490 \pm 100(n=14)$ \\
OMCD & $3.9 \pm 2.27(n=15)$ & $1 \pm 1(n=8)$ \\
& & \\
\hline
\end{tabular}

buffer at $\mathrm{pH}$ ranging from $\mathrm{pH} 5.4$ to 8.0. Renin was measured with an antibody trapping technique using purified homologous substrate (23). Renin activity is expressed in Goldblatt units (GU), determined by comparison with renin standards from the Institute of Medical Research (Medical Research Council, Holly Hill, London).

Statistical analysis. The data are expressed as mean \pm SE. All comparisons were made by an unpaired $t$ test. $P<0.05$ was considered significant.

\section{Results}

Renin activity. Results from measurements of tissue renin activity are summarized in Table I. Tissue renin activity was highest in glomeruli, averaging $405 \pm 120 \mu \mathrm{GU} /$ glomerulus. It is likely that glomerular renin activity reflects the presence of granular cells in the dissected specimens. Substantial renin activity, $51 \pm 15 \mu \mathrm{GU} / \mathrm{mm}$, was also found in PCT. In contrast, renin activity in both PST and OMCD was not significantly different from zero. While the renin content in the dissection dish increased measurably during the one hour of dissection, no renin was found in the washing medium even from specimens obtained at one hour. The absence of renin in PST and OMCD argues against unrecognized contamination of tissue renin with renin secreted into the medium. To obtain information about the identity of the angiotensin I generating activity in tubules and glomeruli, we determined the $\mathrm{pH}$ optimum of glomerular and tubular renin-like activity. As shown in Fig. 3, renin activity from both glomeruli and proximal convoluted tubules had an identical $\mathrm{pH}$ optimum of between 7.0-7.5, suggesting that the enzyme catalyzing angiotensin I formation in the two locations is the same.

Renin $m R N A$. Renin mRNA as assessed by a quantitative PCR method was detectable at approximately equal levels in cDNA prepared from PCT and PST. In contrast, no renin PCR product was amplified in cDNA derived from OMCD. The abundance of renin mRNA in the proximal tubule segments was at least two orders of magnitude lower than that of glomeru-

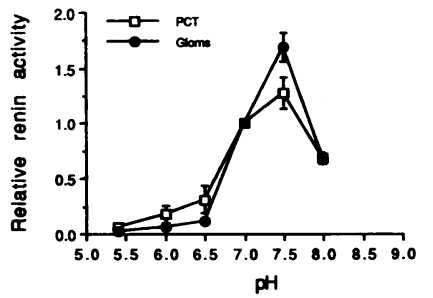

Figure 3. Determination of optimal $\mathrm{pH}$ for glomerular and tubule renin activity. The data indicate ratios of renin activity determined at various $\mathrm{pH}$ to that obtained at $\mathrm{pH} 7$. Each number represents an average of renin activity from three samples. Renin activity from both glomeruli and tubules had a $\mathrm{pH}$ optimum of 7.0 to 7.5 . 
A

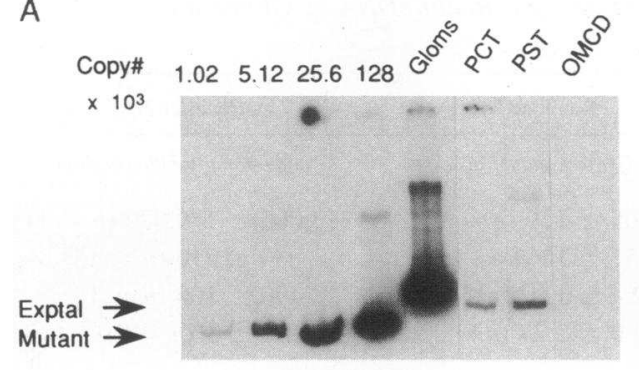

B



Figure 4. (A) Representative autoradiograph of quantitative PCR for glomerular and tubule renin. A dilution series of the mutant template was amplified in parallel with initial cDNA prepared from either dissected glomeruli or proximal tubule (Exptal) in the same PCR run. Renin PCR product from glomeruli yielded higher amounts, PCR product from proximal tubules yielded lower, and equal amounts between PCT and PST. Renin PCR product from OMCD was undetectable. (B) Representative autoradiographs of competitive PCRs for glomerular and tubule renin. Each PCR reaction contained a constant aliquot of experimental cDNA and a dilution series of the mutant template. Glomerular renin yielded PCR product bands with high density, while PCR products from proximal tubules showed much lower amounts but they were easily detectable.

lar renin mRNA. Fig. 4 shows examples for the two methods of quantitation used in this study. In method 1 , glomerular or tubular cDNA was amplified in parallel with the mutant template in the same PCR run (Fig. 4A). In method 2, the cDNA prepared from glomeruli or tubules was coamplified with the dilution series of the mutant template (Fig. $4 B$ ). The log molecular copy number of the mutant template was plotted against log radioactive counts of the PCR product, and the amount of cDNA was calculated from the intersection of the individual regression lines. Relative cDNA copy numbers in glomeruli and tubules are included in Table I. It can be seen that $1 \mathrm{~mm}$ of proximal convoluted or proximal straight tubules had a renin cDNA level of $580 \pm 210$ and $490 \pm 100$ copies, respectively, whereas glomerular renin cDNA amounted to $313 \pm 17.9 \times 10^{3}$ copies. Thus, the amount of renin mRNA in cDNA prepared from $1 \mathrm{~mm}$ proximal tubule was $\sim 500$-fold lower than the amount detected in a single glomerulus.

To determine whether the sequences of tubular and glomerular renin cDNA are identical, PCR products from PCT and PST were digested with restriction enzymes. As shown in Fig. 5, products of cDNA from both proximal segments following di-

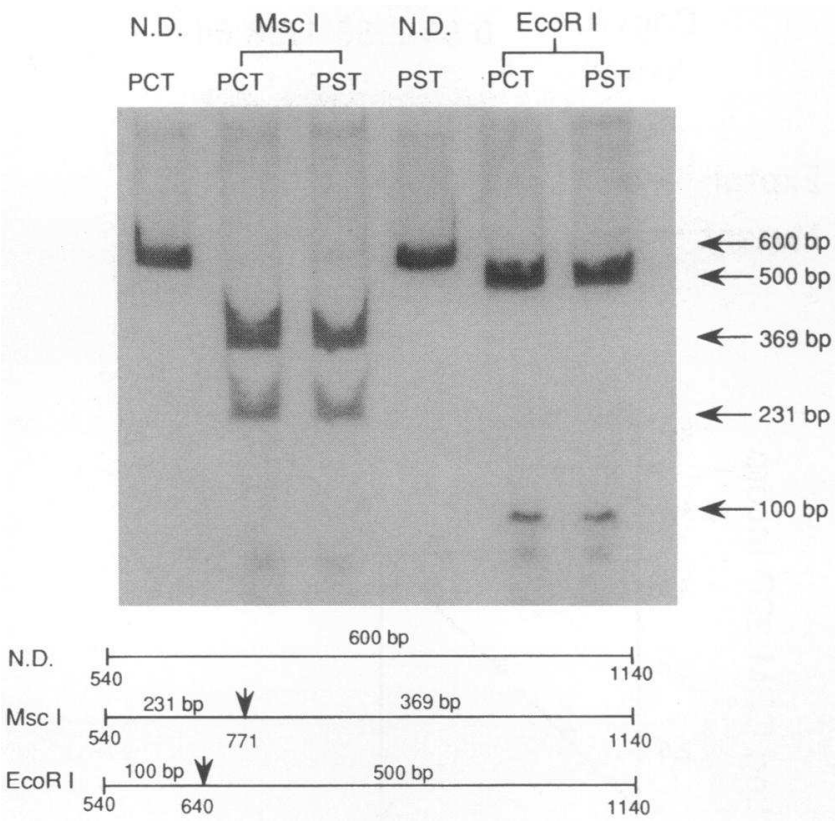

Figure 5. Restriction digestion of tubule renin PCR product. (Top) Autoradiograph of nondigested (N.D.) and digested tubule renin PCR product. (Bottom) Restriction map. Numbers below each lines indicate base pair positions.

gestion with MscI and EcoRI were identical to those predicted from the structure of rat kidney renin cDNA (21).

Effect of converting enzyme inhibition on renin $m R N A$ levels. The effect of CEI was examined in nine separate experiments. In order to assure that renin gene expression was stimulated with CEI treatment in our experiments, two separate PCR runs were performed to determine renin mRNA isolated from the right kidney cortex of rats. The left kidneys of these rats were used for microdissection. Renin mRNA levels in kidney cortex increased $2.86 \pm 1.22$-fold compared to control $(n=3)$ (see Fig. 6). Glomerular renin activity was stimulated substantially by CEI treatment, whereas it decreased significantly in PCT. Consistent with increasing renin mRNA levels in cortical tissue, glomerular renin mRNA levels increased in CEI-treated animals; however, renin mRNA levels in PCT and PST did not change significantly after treatment with CEI. Fig. 7 displays results of renin activity and renin mRNA levels in glomeruli and tubules in control and CEI-treated rats.

\section{Discussion}

The present results show that renin mRNA can be detected in both proximal convoluted and proximal straight tubules of untreated control rats. The levels of renin mRNA in these segments were about the same, and clearly distinguishable from the negative reactions with cDNA derived from outer medullary collecting ducts. Thus, aside from intrarenal vessels, the renin gene is expressed along the proximal tubule, but not in the collecting duct. Since renin substrate and converting enzyme activity is present in proximal tubule cells $(6-12)$, generation of angiotensin II at the level of the proximal tubule would appear possible.

It is important to point out, however, that the levels of 


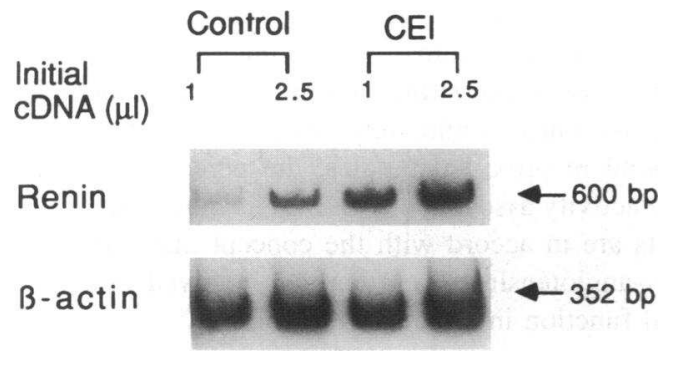

Figure 6. Autoradiographs of representative renin and $\beta$-actin PCR from CEI treated series. PCR was performed using CDNA prepared from kidney cortex with 1 and $2.5 \mu \mathrm{l}$ initial amounts for each sample for renin (top) and for $\beta$-actin (bottom). In this pair of PCR determinations, the increase in renin mRNA levels was 3.4-fold.

proximal tubule renin mRNA are very low. The copy number of total tubular renin cDNA yields a value of about $1.4 \times 10^{8}$, whereas the sum of glomerular renin cDNA copies amounts to about $9.4 \times 10^{9}$ (assuming 30,000 nephrons per kidney and a total length of the proximal tubule of $9 \mathrm{~mm}$ ). Thus, only about $1 \%$ of total renin mRNA in the renal cortex is found in proximal tubules. A relatively low level of renin gene expression in proximal tubules is consistent with the negative outcome of earlier attempts to demonstrate renin mRNA in these cells. If one assumes that the sensitivity of RT-PCR is much greater than in situ hybridization methods, the failure to observe renin mRNA with in situ hybridization in the proximal tubule is quite understandable $(14,16-18)$. In one recent study RT-PCR has been applied to the question of proximal tubule renin gene expression
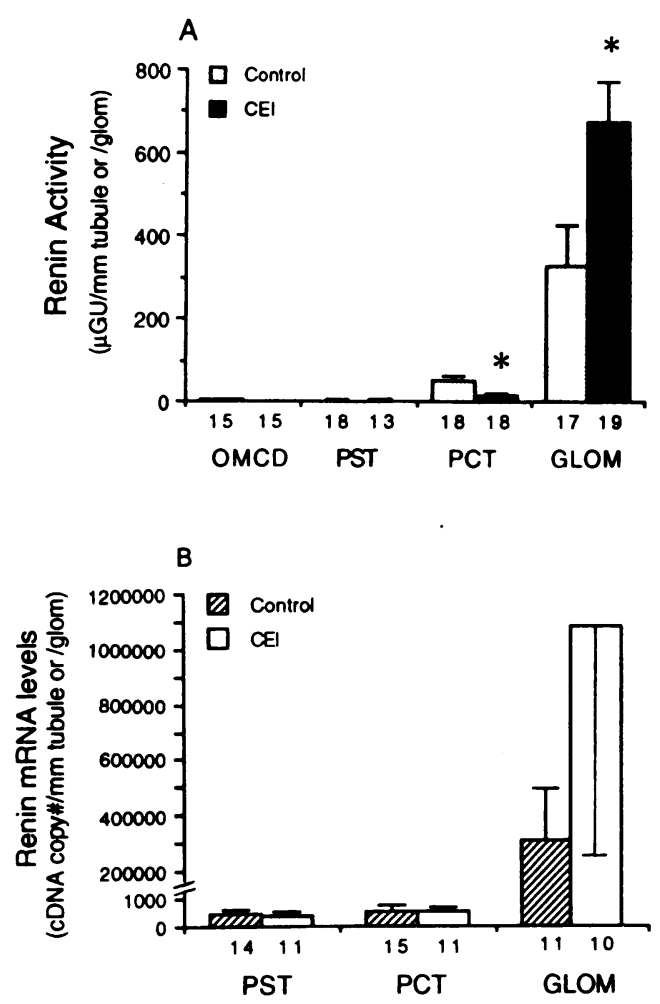

Figure 7. (A) Effect of CEI on renin activity in tubules and glomeruli. $(B)$ Effect of CEI on renin mRNA levels in tubules and glomeruli. Figures below each column indicate number of segments. ${ }^{*} P<0.02$.
(19). Renin PCR products were only seen in cultured proximal tubule cells and in microdissected proximal tubules of CEItreated animals. In contrast to the present experiments, proximal tubules of control rats did not show detectable levels of renin mRNA in three out of four experiments. Differences in animal pretreatment and in PCR methodology may be responsible for these different results, but it is also evident that the differences between these and the present observations may be more of quantitative than qualitative nature. When PCR products were reamplified in a second stage reaction, Moe and his colleagues did, in fact, detect renin product suggesting a low level of renin gene expression (19). In addition, proximal tubule cells in culture have been shown to contain detectable amounts of renin mRNA, but its level was estimated to amount to only $\sim 2-3 \%$ of that in cultured juxtaglomerular cells (19). Thus, all available results appear to be in agreement that renin mRNA levels in the proximal tubule are very low and may only be detectable under certain optimized conditions. Whether such low levels of renin can generate enough angiotensin I to result in the observed levels of angiotensin II in proximal tubular fluid is uncertain.

In contrast to the low levels of renin mRNA in proximal tubular epithelium, renin content along this nephron segment was found to be surprisingly high. Renin activity measured as angiotensin I generating capacity was only about eightfold higher in one glomerulus than in $1 \mathrm{~mm}$ of proximal tubule (compared to a ratio of 500:1 for renin mRNA). Since glomerular protein content or tissue mass of $1 \mathrm{~mm}$ of PCT is about 1.5fold higher than that of one glomerulus, glomerular renin activity per unit tissue mass is about 10 -fold higher than tubular renin activity. Considering a length of proximal convoluted tubules of about $6 \mathrm{~mm}$, the total amount of proximal tubular renin can be estimated to be approximately half the total amount of glomerular renin. This relationship is most certainly an underestimation of the difference between glomerular and tubular renin since only a fraction of all granular cells in the juxtaglomerular apparatus is likely to be included in our dissected glomerular specimen. Nevertheless, our observations are in accord with the earlier immunocytochemical demonstrations of substantial amounts of renin in proximal tubular epithelium (24-26).

The presence of renin mRNA in the proximal tubule would appear to support the concept that the renin activity found in the cells of the proximal epithelium is derived from renin synthesis. While some of the proximal epithelial renin may, in fact, originate from translation of proximal tubule renin transcripts, it is unclear whether this is the only pathway responsible for the presence of the enzyme in this location. It is of concern that no measurable renin activity was seen in proximal straight tubules even though the level of renin mRNA was not significantly lower than in the convoluted segments. It is possible that renin generated in the S3 segments is not stored intracellularly to any measurable extent or that the protein is exceptionally unstable. On the other hand, some other mechanism, in addition to translation of renin mRNA, may participate in elevating renin substrate cleavage in the convoluted portion of the tubule. One possibility is that the generation of angiotensin I may be catalyzed by some enzyme other than renin. In fact, both cathepsin D and kallikrein have been shown to be able to generate angiotensin II from angiotensinogen $(28,29)$. However, the $\mathrm{pH}$ optimum for angiotensin formation by both the lysosomal cathepsins and by kalli-

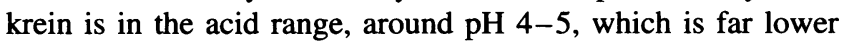
than the neutral $\mathrm{pH}$ found to be optimal for the interaction of 
renin with species-specific angiotensinogen (30). In addition, kallikrein is not found in the proximal tubule. Tonin has been described as an enzyme that can cleave angiotensin II directly from angiotensinogen $(31,32)$. Although this enzyme may play a role in angiotensin II formation in the proximal tubule, it is unlikely to be responsible for the angiotensin generating activity in the proximal tubule in our experiments since angiotensin I formation was measured.

Alternatively, as suggested by Taugner et al. (24-26), it is possible that the immunocytochemical evidence for proximal tubule renin may reflect uptake of filtered renin by endocytosis rather than formation of new renin (27). Support for this notion is the finding that labeling of proximal apical vesicles could be found following intravenous injection of radioactive renin. Furthermore, absorption of filtered renin by proximal tubule cells has been shown by micropuncture (33). Since the fusion of endosomes with lysosomes and the lysosomal protein degradation are relatively slow processes (34), one may assume that renin taken up into endocytic vesicles retains its enzymatic activity for some time, so that renin-containing vesicles could contribute to the angiotensin generating activity of proximal tubules. This may at least in part explain why renin activity in proximal straight tubules was not clearly detectable since protein uptake, the presence of the endosomal-lysosomal machinery, and the abundance of lysosomal enzymes are all less pronounced in S3 than in S1 and S2 proximal segments (34). Furthermore, the medium of primary cultures of proximal tubule cells has been shown to accumulate renin in a time-dependent and regulated fashion suggesting continued secretion of renin. However, the renin activity in lysed cells was low or even undetectable $(19,35)$. It is conceivable that this dissociation between secretion and content is the result of reduced renin endocytosis as a consequence of the presumably low renin concentration in the large volume of the culture medium.

Our results confirm earlier studies showing that the administration of a converting enzyme inhibitor for two days caused a significant increase in renin activity in dissected glomeruli (19). Similarly, glomerular renin mRNA levels were found to be increased during converting enzyme inhibition (18). In contrast to the stimulatory effect of this treatment on glomerular renin activity and renin mRNA, we were unable to find increments in renin content or renin gene expression in any of the tubule segments tested. In the earlier study of Moe et al., converting enzyme inhibition appeared to elevate renin mRNA levels into the detectable range in the $\mathrm{S} 2$ segment of the proximal tubule, but usually not in S1 or S3 segments (19). Even though we did not systematically determine the origin of our proximal tissue samples, it seems highly unlikely that S2 segments were consistently not harvested in our study. While it is possible that the shorter duration of converting enzyme treatment in our experiments compared to the study by Moe et al. is responsible for the difference in results, the increase in cortical and glomerular renin mRNA supports the efficacy of the CEI treatment protocol used in our studies (19). On the other hand, our results may indicate that the regulation of renin gene expression in glomeruli and in the proximal tubule may be governed by different factors.

In summary, the results of the present study show that both proximal convoluted and proximal straight tubules, but not outer medullary collecting ducts, express the renin gene even though the number of copies per mm of PCT is only about 1/500th of the copy number found in one glomerulus. Significant renin enzymatic activity, amounting to about $1 / 8$ th of that in one glomerulus, was found in $1 \mathrm{~mm}$ of PCT, while renin activity was not detectable in proximal straight tubules or outer medullary collecting ducts. Thus, while only about $1 \%$ of total renin mRNA is found in proximal tubules, the percentage of total renin enzyme activity associated with PCT is much higher. The present results are in accord with the concept that a proximal tubular renin-angiotensin system may be involved in controlling epithelial function in a paracrine fashion.

\section{Acknowledgments}

This work was supported by National Institute of Diabetes and Digestive and Kidney Diseases grants DK-37448, DK-39255, and DK-40042. M. P. Harris was the recipient of a summer stipend of the University of Michigan Summer Program for Student Biomedical Research.

\section{References}

1. Geibel, J., G. Giebisch, and W. F. Boron. 1990. Angiotensin II stimulates both $\mathrm{Na}^{+}-\mathrm{H}^{+}$exchange and $\mathrm{Na}^{+} / \mathrm{HCO}_{3}^{-}$cotransport in the rabbit proximal tubule. Proc. Natl. Acad. Sci. USA. 87:7917-7920.

2. Saccomani, G., K. D. Mitchell, and L. G. Navar. 1990. Angiotensin II stimulation of $\mathrm{Na}^{+}-\mathrm{H}^{+}$exchange in proximal tubule cells. Am. J. Physiol. 258:F1188-F1195.

3. Douglas, J. G. 1987. Angiotensin receptor subtypes of the kidney cortex. Am. J. Physiol. 253:F1-F7.

4. Braam, B., K. D. Mitchell, J. Fox, and L. G. Navar. 1993. Proximal tubular secretion of angiotensin II in rats. Am. J. Physiol. 264:F891-F898.

5. Seikaly, M. G., B. S. Arant, and F. D. Seney. 1990. Endogenous angiotensin concentrations in specific intrarenal fluid compartments of the rat. J. Clin. Invest. 86:1352-1357.

6. Richoux, J. P., J. L. Cordonnier, J. Bouhnik, E. Clauser, P. Corvol, J. Menard, and G. Grignon. 1983. Immunocytochemical localization of angiotensinogen in rat liver and kidney. Cell Tissue Res. 233:439-451.

7. Campbell, D. J., and J. H. Habener. 1987. Regional distribution of angiotensinogen messenger RNA in rat adrenal and kidney. J. Hypertens. 4:S385-S387.

8. Ingelfinger, J. R., W. M. Zuo, E. A. Fon, K. E. Ellison, and V. J. Dzau. 1990. In situ hybridization evidence for angiotensinogen mRNA in the rat proximal tubule. J. Clin. Invest. 85:417-423.

9. Bruneval, P., N. Hinglais, F. Alhenc-Gelas, V. Tricottet, P. Corvol, J. Menard, J. P. Camilleri, and J. Bariety. 1986. Angiotensin I converting enzyme in human intestine and kidney. Ultrastructural immunohistochemical localization. Histochemistry. 85:73-80.

10. Rix, E., D. Ganten, B. Schüll, T. Unger, and R. Taugner. 1981. Convertingenzyme in the choroid plexus, brain, and kidney: immunocytochemical and biochemical studies in rats. Neurosci. Lett. 22:125-130.

11. Takada, Y., K. Hiwada, M. Unno, and T. Kokubu. 1982. Immunocytochemical localization of angiotensin converting enzyme at the ultrastructural level in the human lung and kidney. Biomed. Res. 3:169-174.

12. Ward, P. E., C. D. Gedney, R. M. Dowben, and E. G. Erdös. 1975. Isolation of membrane-bound renal kallikrein and kininase. Biochem. J. 151:755758.

13. Taugner, C., K. Poulsen, E. Hackenthal, and R. Taugner. 1979. Immunocytochemical localization of renin in mouse kidney. Histochemistry. 62:19-27.

14. Deschepper, C. F., S. H. Mellon, F. Cumin, J. D. Baxter, and W. F. Ganong. 1986. Analysis by immunocytochemistry and in situ hybridization of renin and its mRNA in kidney, testis, adrenal and pituitary of rat. Proc. Natl. Acad. Sci. USA. 83:7552-7556.

15. Menard, J., P. W. N'Goc, J. Bariety, P. T. Guyenne, and P. Corvol. 1979. Direct radioimmunoassay and immunocytochemical localization of renin in human kidneys. Clin. Sci. 57[Suppl. 5]:105-108.

16. Dzau, V. J., K. E. Ellison, T. Brody, J. Ingelfinger, and R. E. Pratt. 1987. A comparative study of the distribution of renin and angiotensinogen messenger ribonucleic acids in rat and mouse tissues. Endocrinology. 120:2334-2338.

17. Schunkert, H., J. R. Ingelfinger, and V. J. Dzau. 1991. Evolving concepts of the intrarenal renin-angiotensin system in health and disease: contributions of molecular biology. Ren. Physiol. Biochem. 14:146-154.

18. Gomez, R. A., K. R. Lynch, B. C. Sturgill, J. P. Elwood, R. L. Chevalier, R. M. Carey, and M. J. Peach. 1989. Distribution of renin mRNA and its protein in the developing kidney. Am. J. Physiol. 257:F850-F858.

19. Moe, O. W., K. Ujiie, R. A. Star, R. T. Miller, J. Widell, R. J. Alpern, and W. L. Henrich. 1993. Renin expression in renal proximal tubule. J. Clin. Invest. 91:774-779.

20. Strauss, F., and A. Varshavsky. 1984. A protein binds to a satellite DNA 
repeat at three specific sites that would be brought into mutual proximity by DNA folding in the nucleosoine. Cell. 37(3):889-901.

21. Burnham, C. E., C. L. Hawelu-Johnson, B. M. Frank, and K. R. Lynch. 1987. Molecular cloning of rat renin cDNA and its gene. Proc. Natl. Acad. Sci. USA. 84:5605-5609.

22. Gunning, P., P. Ponte, H. Okayama, J. Engel, H. Blau, and L. Kedes. 1983. Isolation and characterization of full-length cDNA clones for human alphabeta, and gamma-actin mRNAs: Skeletal but not cytoplasmic actins have an amino-terminal cysteine that is subsequently removed. Mol. Cell. Biol. 3(5):787795.

23. Lykkegard, S., and K. Poulsen. 1976. Ultramicroassay for plasma renin concentration in the rat using the antibody-trapping technique. Anal. Biochem. 75:250-259.

24. Taugner, R., E. Hackenthal, R. Nobiling, M. Harlacher, and G. Reb. 1981. The distribution of renin in the different segments of the renal arterial tree. Histochemistry. 73:75-88.

25. Taugner, R., E. Hackenthal, T. Inagami, R. Nobiling, and K. Poulsen 1982. Vascular and tubular renin in the kidneys of mice. Histochemistry. 75:473484.

26. Taugner, R., S. J. Kim, K. Murakami, and R. Waldherr. 1987. The fate of prorenin during granulopoiesis in epithelioid cells. Immunocytochemical experiments with antisera against renin and different portions of the renin prosegment. Histochemistry. 86:249-253.
27. Iwao, H., N. Nakamura, F. Ikemoto, K. Yamamoto, V. Mizuhira, M. Ono, and Y. Sugiura. 1982. Distribution of exogenously administered renin in mouse kidney. 1982. Clin. Exp. Hypertens. [A] 4:2449-2456.

28. Maruta H., and K. Arakawa. 1983. Confirmation of direct angiotensin formation by kallikrein. Biochem. J. 213:193-200.

29. Day, R. P., and I. A. Reid. 1976. Renin activity in dog brain: enzymological similarity to cathepsin D. Endocrinology. 99:93-100.

30. Inagami, T. 1993. Renin: purification, structure, and function. In The Renin-Angiotensin System. J. I. S. Robertson and M. G. Nicholls, editors. Gower Medical Publishing, London/New York. Vol. 1, 4.1-4.17.

31. Hackenthal, E., C. Koch, T. Bergemann, and F. Gross. 1972. Partia purification and characterization of a renin-like enzyme from rat submandibular gland. Biochem. Pharmacol. 21:2779-2792.

32. Boucher, R., J. Asselin, and J. Genest. 1974. A new enzyme leading to the direct formation of angiotensin II. Circ. Res. 34/35 [Suppl. 1]:203-209.

33. Leyssac, P. P. 1978. A micropuncture study of glomerular filtration and tubular reabsorption of endogenous renin in the rat. Renal Physiol. 1:181-188.

34. Maack, T., C. H. Park, and M. J. F. Camargo. 1992. Renal regulation of proteins and macromolecules: normal. In The Kidney, Physiology and Pathophysiology. 2nd Edition. W. D. Seldin and G. Giebisch, editors. Raven Press, New York. 3005-3038.

35. Yanagawa, N., A. W. Capparelli, O. D. Jo, A. Friedal, J. D. Barrett, and P. Eggena. 1991. Production of angiotensinogen and renin-like activity by rabbit proximal tubular cells in culture. Kidney Int. 39:938-941. 